8. Leznoff, C. C. \& Lever, A. B. P. (eds) Phthalocyanines: Properties and Applications (VCH, New York, 1989).

9. Wang, L. S., Ding, C. F., Wang, X. B. \& Barlow, S. E. Photodetachment photoelectron spectroscopy of multiply charged anions using electrospray ionization. Rev. Sci. Instrum. 70, 1957-1966 (1999).

10. Berkowitz, J. Photoelectron spectroscopy of phthalocyanine vapors. J. Chem. Phys. 70, 2819-2828 (1979).

11. Brown, C. J. Crystal structure of $\beta$-copper phthalocyanine. J. Chem. Soc. A 2488-2493 (1968).

12. Rosa, A. \& Baerends, E. J. Metal-macrocycle interaction in phthalocyanines: density functional calculations of ground and excited states. Inorg. Chem. 33, 584-595 (1994).

13. PC Spartan Plus 5.1 (Wavefunction, Inc, Von Carman Ave., Irvine, California 92612, USA).

14. Stewart, J. J. Optimization of parameters for semiempirical methods II: Applications. J. Comput Chem. 10, 221-264 (1989); MOPAC: A semiempirical molecular orbital program. J. Comput. Aided Mol. Design 4, 1-105 (1990).

15. D'Haennens, I. J. in Encyclopedia of Physics (eds Lerner, R. G. \& Trigg, G. L.) 1251-1253 (VCH, New York, 1991).

16. Hodgson, P. E., Gadioli, E. \& Erba, E. G. Introductory Nuclear Physics (Clarendon, Oxford, 1997).

17. Scheller, M. K. \& Cederbaum, L. S. A construction principle for stable multiply charged molecular anions in the gas phase. Chem. Phys. Lett. 216, 141-146 (1993).

18. Weikert, H.-G. \& Cederbaum, L. S. Free doubly negative tetrahalides. J. Chem. Phys, 99, 8877-8891 (1993).

19. Boldyrev, A. I., Gutowski, M. \& Simons, J. Small multiply charged anions as building blocks in chemistry. Acc. Chem. Res. 29, 497-502 (1996).

20. Vekey, K. Multiply charged ions. Mass Spectrom. Rev. 14, 195-225 (1995).

21. Brechignac, C., Cahuzac, P., Kebaili, N. \& Leygnier, J. Temperature effects in the Coulombic fission of strontium clusters. Phys. Rev. Lett. 81, 4612-4615 (1998).

22. Schroder, D., Harvey, J. N. \& Schwarz, H. Long-lived, multiply charged diatomic $\operatorname{TiF}^{\mathrm{nt}}$ ions $(\mathrm{n}=1-3)$ J. Phys. Chem. A 102, 3639-3642 (1998).

Acknowledgements. We thank R. S. Disselkamp for discussions and K. Ferris for help in the theoretica calculations. This work was supported by the US Department of Energy, Office of Basic Energy Sciences, Chemical Sciences Division and is conducted at the Pacific Northwest National Laboratory operated for the US Department of Energy by Battelle Memorial Institute. L.-S.W. is an Alfred P. Sloan research fellow.

\section{Dual modes of the} carbon cycle since the Last Glacial Maximum

\section{H. Jesse Smith ${ }^{\star}$, H. Fischer ${ }^{\star}$, M. Wahlen ${ }^{\star}$, D. Mastroianni ${ }^{\star}$ \& B. Deck ${ }^{\star}$}

* Scripps Institution of Oceanography, University of California San Diego, La Jolla, California 92093-0220, USA

The most conspicuous feature of the record of past climate contained in polar ice is the rapid warming which occurs after long intervals of gradual cooling. During the last four transitions from glacial to interglacial conditions, over which such abrupt warmings occur, ice records indicate that the $\mathrm{CO}_{2}$ concentration of the atmosphere increased by roughly 80 to 100 parts per million by volume (refs 1-4). But the causes of the atmospheric $\mathrm{CO}_{2}$ concentration increases are unclear. Here we present the stablecarbon-isotope composition $\left(\delta^{13} \mathrm{CO}_{2}\right)$ of $\mathrm{CO}_{2}$ extracted from air trapped in ice at Taylor Dome, Antarctica, from the Last Glacial Maximum to the onset of Holocene times. The global carbon cycle is shown to have operated in two distinct primary modes on the timescale of thousands of years, one when climate was changing relatively slowly and another when warming was rapid, each with a characteristic average stable-carbon-isotope composition of the net $\mathrm{CO}_{2}$ exchanged by the atmosphere with the land and oceans. $\delta^{13} \mathrm{CO}_{2}$ increased between 16.5 and 9 thousand years ago by slightly more than would be estimated to be caused by the physical effects of a $5{ }^{\circ} \mathrm{C}$ rise in global average sea surface temperature driving a $\mathrm{CO}_{2}$ efflux from the ocean, but our data do not allow specific causes to be constrained.

Carbon dioxide in the atmosphere causes a radiative forcing second only to water vapour, and so may be a central agent in climate change. Polar ice cores contain a detailed record of climate-

$\dagger$ Present address: Alfred-Wegener-Institute for Polar and Marine Research, Columbusstrasss, D-27515 Bremerhaven, Germany. related variables which extends more than 400,000 years into the past $^{4}$, and are especially valuable for studying variations of atmospheric $\mathrm{CO}_{2}$ as they contain an effectively direct record, unlike atmospheric proxies such as marine carbonates or preserved organic material ${ }^{5}$ which may also reflect biological effects. Ice cores from Antarctica, such as those of Taylor Dome and Vostok, are the best sources for palaeoatmospheric $\mathrm{CO}_{2}$ measurements because they contain only small amounts of the kinds of chemical impurities, such as carbonate dust or organic acids, that may lead to contamination by in situ $\mathrm{CO}_{2}$ production ${ }^{2,6-8}$. Taylor Dome ice has the additional advantage that the entire 554-m-long core is from above the depth at which air trapped in bubbles in the ice forms gas-ice clathrates. This feature is important because, as we have found, the accuracy of $\delta^{13} \mathrm{CO}_{2}$ measurements performed on bubblefree ice may be affected by the presence of clathrates. $\left(\delta^{13} \mathrm{C}\right.$ is defined in Methods.) We have measured the $\mathrm{CO}_{2}$ concentration and $\delta^{13} \mathrm{CO}_{2}$ of air trapped in ice from Taylor Dome, Antarctica, across the last glacial termination in order to develop a time series for the carbonisotope composition of atmospheric $\mathrm{CO}_{2}$ and to constrain the mechanisms of carbon cycling between the main sources and sinks of atmospheric $\mathrm{CO}_{2}$.

The atmospheric $\mathrm{CO}_{2}$ concentration data ${ }^{3,9}$ (Fig. 1) form a record comparable to that from Byrd and Vostok ${ }^{1,2}$. The salient features include a low but variable concentration of atmospheric $\mathrm{CO}_{2}$ between 27.1 and $18.0 \mathrm{kyr}$ вP (thousand years before present, where "present" is defined as AD 1950), when it varied between 186 and 201 parts per million by volume (p.p.m.v.); a rise, at a fairly constant rate, from 190 p.p.m.v. at $17.0 \mathrm{kyr}$ BP to an early Holocene local maximum of 268 p.p.m.v. at $10.6 \mathrm{kyr}$ BP, punctuated by a shallow minimum at $16.1 \mathrm{kyr}$ BP and a drop of 8 p.p.m.v. between 14 and 13 kyr BP which may be related to the Antarctic Cold Reversal $^{3}$; an 8 p.p.m.v. decrease, from 268 p.p.m.v. at $10.6 \mathrm{kyr}$ вр to 260 p.p.m.v. at $9.1 \mathrm{kyr}$ BP, followed by a rise to the pre-industrial level of about 280 p.p.m.v. (as discussed in detail by Indermühle et $\left.a l .{ }^{9}\right)$. These data can be combined with the carbon-isotope composition of the $\mathrm{CO}_{2}$ to give a better picture of how the carbon cycle operated during this time.

The main features of the carbon-isotope record shown in Fig. 1 include a $0.5 \%$ drop in $\delta^{13} \mathrm{CO}_{2}$ between 18.0 and $16.5 \mathrm{kyr} \mathrm{BP}$, and the subsequent increase of $0.7 \%$, from $-7.0 \%$ o to $-6.3 \%$, between 16.5 and $9.1 \mathrm{kyr} \mathrm{BP}$, which is interrupted by two local $\delta^{13} \mathrm{CO}_{2}$ minima at approximately 13 and $10 \mathrm{kyr}$ вр. The minimumto-maximum $\delta^{13} \mathrm{CO}_{2}$ increase began 1,000 to 2,000 years after $\mathrm{CO}_{2}$ began to rise, and continued to rise for $\sim 3,000$ years after the $\mathrm{CO}_{2}$ concentration maximum at $10.6 \mathrm{kyr} \mathrm{BP}$, which we interpret as a consequence of the bimodality of carbon cycling (discussed below) rather than a decoupling of $\mathrm{CO}_{2}$ concentrations from carbon-isotope compositions. Furthermore, there appears to have been an extended local minimum in $\delta^{13} \mathrm{CO}_{2}$ between 13.4 and 12.3 kyr BP that accompanied the Younger Dryas ${ }^{10}$ but was not concurrent with the $\mathrm{CO}_{2}$ concentration drop at $14 \mathrm{kyr}$ в. The $0.16 \%$ difference between the average $\delta^{13} \mathrm{CO}_{2}$ values of the Last Glacial Maximum (LGM) and Holocene (see Fig. 2 legend for an explanation of these groupings) is similar to the increase of $0.19 \pm 0.18 \%$ ostimated by Leuenberger et al. ${ }^{11}$ to have occurred between the period 20-40 kyr BP and the early Holocene. These data show, however, that there was a significant drop in $\delta^{13} \mathrm{CO}_{2}$ between the end of the LGM and the beginning of the transition, and that the subsequent rise into the early Holocene was much larger than the difference between average values for the LGM and Holocene. Moreover, inferences about the carbon cycle drawn from the comparison of the LGM and Holocene averages may be misleading because there was significant variability within each of those periods, and the averages depend strongly on the interval chosen to calculate them. Finally, the variability of $\delta^{13} \mathrm{CO}_{2}$ before $17.5 \mathrm{kyr}$ вP and after $10.3 \mathrm{kyr} \mathrm{BP}, 0.33 \%$ and $0.37 \%$, respectively, is about half of the magnitude of the 


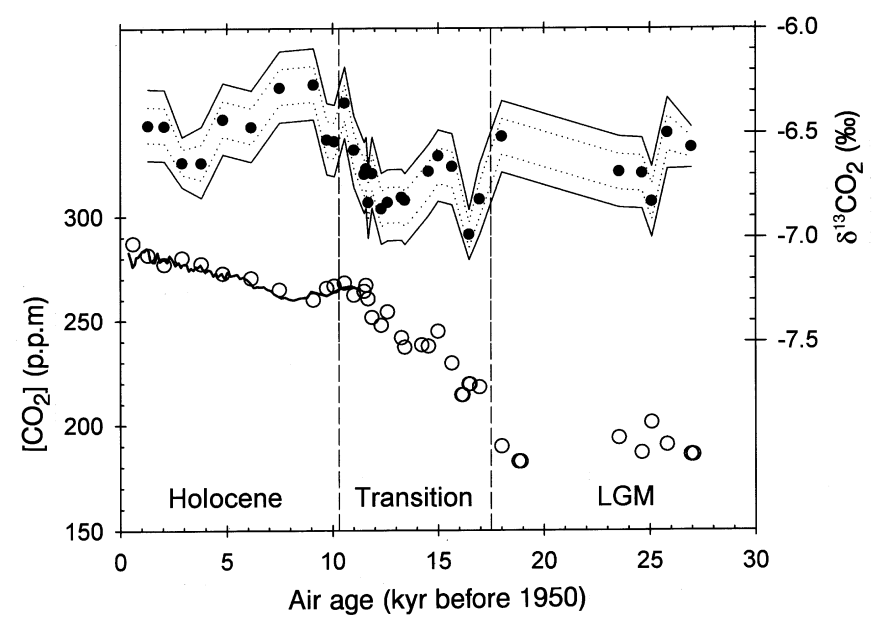

Figure $1 \delta^{13} \mathrm{CO}_{2}$ and $\mathrm{CO}_{2}$-concentration trends. The data are based on measurements of air trapped in ice from Taylor Dome, Antarctica, and are plotted against air age. Upper curve, $\delta^{13} \mathrm{CO}_{2}$ values (filled circles) within envelopes of $1 \sigma$ and $2 \sigma$ uncertainty (indicated as dotted and solid lines, respectively; see the Methods section for details). Lower curve, $\mathrm{CO}_{2}$ concentration data shown as open circles were measured in our laboratory at $\mathrm{SIO}^{3}$, while the solid line shown in the Holocene (for comparison) is the higher-resolution record of Indermühle et al. ${ }^{9}$. The age axis is divided into three intervals, called "LGM", "transition", and "Holocene" on the basis of $\mathrm{CO}_{2}$ concentrations and generally accepted ages for these periods. The LGM group includes all of the points with air ages between 27.1 and $18.0 \mathrm{kyr} \mathrm{BP}$, the youngest being the last with a $\mathrm{CO}_{2}$ concentration below the highest value of the older samples. The transition group includes the points with ages between 17.0 and $10.6 \mathrm{kyr} \mathrm{BP}$, where the local $\mathrm{CO}_{2}$ maximum which we use to define the start of the Holocene occurs. The Holocene group includes all the points with ages between 10.1 and $1.3 \mathrm{kyr} \mathrm{BP}$ (the youngest sample measured for $\delta^{13} \mathrm{CO}_{2}$ ). The boundaries between the LGM and the transition, and between the transition and the Holocene, chosen here to fall at 17.5 and $10.3 \mathrm{kyr}$ BP, respectively, are shown as vertical dashed lines.

increase that occurs during the transition, indicating that carbon cycling also varied considerably over shorter timescales.

The atmospheric portion of the carbon cycle is extremely dynamic; $\sim 20 \%$ of the $\mathrm{CO}_{2}$ in the atmosphere is exchanged with the ocean and terrestrial biosphere every year (ref. 12), so the atmosphere responds very quickly to changes in $\mathrm{CO}_{2}$ cycling between these three reservoirs. The exchange of carbon can affect the isotopic composition of atmospheric $\mathrm{CO}_{2}$ for two reasons. First, the reservoirs have different carbon-isotope compositions (the $\delta^{13} \mathrm{CO}_{2}$ of the ocean is close to $0 \%$, the terrestrial biosphere has a $\delta^{13} \mathrm{CO}_{2}$ of approximately $-25 \%$ and that of pre-industrial atmosphere was approximately $-6.5 \%$; ref. 13). Second, each flux of $\mathrm{CO}_{2}$ between the atmosphere and either the ocean or the terrestrial biosphere is accompanied by a different carbon-isotope fractionation, resulting in isotopically unique values of $\delta^{13} \mathrm{CO}_{2}$ for each transfer. Consequently, variations in the carbon-isotope composition of atmospheric $\mathrm{CO}_{2}$ can be caused by a net flux of carbon between reservoirs, or by a change in the isotopic fractionation associated with a particular atmospheric flux. It also follows from this that the carbon-isotope composition of the net atmospheric $\mathrm{CO}_{2}$ exchanged, $\delta^{13} \mathrm{CO}_{2}(\mathrm{ex})$, is a function of the relative strengths of processes which transfer $\mathrm{CO}_{2}$ into and out of the atmosphere, so different $\delta^{13} \mathrm{CO}_{2}(\mathrm{ex})$ values indicate different balances of processes. When a unique balance of processes persists over thousands of years, as indicated by a unique $\delta^{13} \mathrm{CO}_{2}(\mathrm{ex})$, we refer to it as a 'mode' of the carbon cycle.

In order to examine more closely the implications of the time series shown in Fig. 1, it is advantageous to consider the three data groups (LGM, transition and Holocene) individually. Doing so in

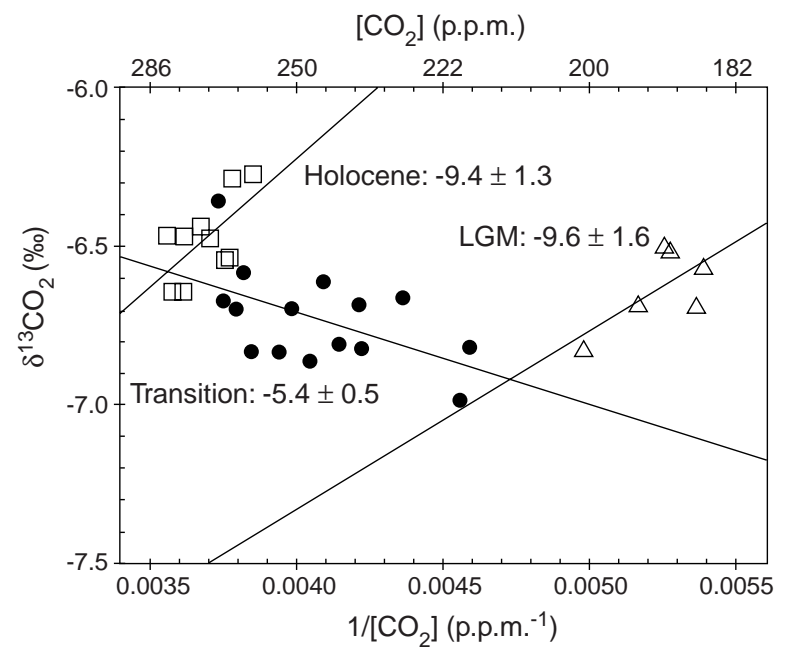

Figure 2 Mixing diagram for Taylor Dome samples: $1 /\left[\mathrm{CO}_{2}\right]$ is plotted against $\delta^{13} \mathrm{CO}_{2}$. The data are divided into three groups, as described in the figure: the LGM group (open triangles, $6 \delta^{13} \mathrm{CO}_{2}$ points), the transition group (filled circles, $15 \delta^{13} \mathrm{CO}_{2}$ points), and the Holocene group (open squares, $10 \delta^{13} \mathrm{CO}_{2}$ points). The $y$-intercept of the regression line through each of the three groups of data, along with the corresponding $1 \sigma$ uncertainty for each value, indicates the $\delta^{13} \mathrm{C}$ of the $\mathrm{CO}_{2}$ exchanged by the atmosphere, $\delta^{13} \mathrm{CO}_{2}(\mathrm{ex})$, and is shown on the figure.

Fig. 2 reveals a relationship between the concentration of atmospheric $\mathrm{CO}_{2}$ and its carbon-isotope composition during each of these intervals. (Figure 2 is a mixing diagram, where the inverse $\mathrm{CO}_{2}$ concentration is plotted against $\delta^{13} \mathrm{CO}_{2}$, so that addition or removal of $\mathrm{CO}_{2}$ with a given $\delta^{13} \mathrm{C}$ would appear as a nearly straight line with the $y$-intercept approximately equal to the isotopic composition of the net $\mathrm{CO}_{2}$ added to, or subtracted from, the atmosphere.) The coherent trends displayed by these groups show that the carbon cycle has operated in two distinct modes over the past $27 \mathrm{kyr}$, one during the Holocene, and possibly the LGM as well, when the average $\delta^{13} \mathrm{C}$ of net $\mathrm{CO}_{2}$ exchanged was approximately $-10 \%$, and another during the transition, when the average $\delta^{13} \mathrm{C}$ of net $\mathrm{CO}_{2}$ exchanged was approximately $-5 \%$. In other words, during the period of relatively stable, slowly changing climate of the Holocene, the carbon of the net exchanged atmospheric $\mathrm{CO}_{2}$ was isotopically lighter than the average atmospheric value (that is, $\mathrm{d} \delta{ }^{13} \mathrm{CO}_{2} / \mathrm{dCO}_{2}$ was negative). In contrast, during the period of rapidly changing climate of the transition the net exchanged $\mathrm{CO}_{2}$ was isotopically heavier $\left(\mathrm{d} \delta{ }^{13} \mathrm{CO}_{2} / \mathrm{dCO}_{2}\right.$ was positive). Therefore, these data suggest that the carbon cycle has operated in two primary modes over the past $27 \mathrm{kyr}$, one when climate is changing only slowly and another when rapid warming occurs, and that although there are clearly other processes which have affected atmospheric $\mathrm{CO}_{2}$ over the past $27 \mathrm{kyr}$, as is evident from the scatter in the data shown in Fig. 2, those transient variations did not overwhelm the longer-term trends.

Many schemes have been advanced to account for the magnitude of the rise in the concentration of atmospheric $\mathrm{CO}_{2}$ during deglaciations (see, for example, Broecker ${ }^{14}$ for a critical review), although none seem to be uniquely sufficient. Two factors which must be included in any analysis of the glacial-interglacial increase in atmospheric $\mathrm{CO}_{2}$ content, however, are a rise in sea surface temperature (SST) and a decrease in ocean salinity (S). In the range of SST, atmospheric $\mathrm{CO}_{2}$ concentration and salinity appropriate for this study, changes in SST affect both atmospheric $p_{\mathrm{CO}}$ and $\delta^{13} \mathrm{CO}_{2}$, by approximately $4.2 \%$ per ${ }^{\circ} \mathrm{C}$ (ref. 15 ) and $0.11-0.13 \%$ per ${ }^{\circ} \mathrm{C}$ (ref. 16 ), respectively, while changes in salinity alter $p_{\mathrm{CO}_{2}}$ by 10 p.p.m.v. per $\% \mathrm{o}$ without affecting its $\delta^{13} \mathrm{C}$ (ref. 17). Measurements performed on tropical corals show that SST increased by $5-6{ }^{\circ} \mathrm{C}$ from 
the last peak-glacial period to the early Holocen $e^{18}$, significantly more than the earlier estimate of $1-2{ }^{\circ} \mathrm{C}$ by CLIMAP ${ }^{19}$, while the change in ocean salinity, estimated from sea level change ${ }^{20}$, was approximately $-1.4 \%$. Assuming a global average $\Delta$ SST (sea surface temperature change) of $5{ }^{\circ} \mathrm{C}$, the combined effects of temperature and salinity changes should have resulted in increases in the concentration and $\delta^{13} \mathrm{CO}_{2}$ of roughly 30 p.p.m.v. and $0.6 \%$, respectively. If this were true, then all other processes which caused variations in atmospheric $\mathrm{CO}_{2}$ must together have increased its concentration by $\sim 50$ p.p.m.v. and its $\delta^{13} \mathrm{CO}_{2}$ by only $0.1 \%$. A $2{ }^{\circ} \mathrm{C}$ global average $\Delta$ SST, on the other hand, would have caused no significant change in the concentration of atmospheric $\mathrm{CO}_{2}$ and increased $\delta^{13} \mathrm{CO}_{2}$ by roughly $0.2 \%$, leaving unexplained an approximately 80 p.p.m. concentration increase and a $0.5 \%$ $\delta^{13} \mathrm{CO}_{2}$ increase. Adding these changes to the $0.3 \%$ whole-ocean $\delta^{13} \mathrm{CO}_{2}$ increase which is thought to have accompanied deglaciation ${ }^{21}$, the expected increase in atmospheric $\delta^{13} \mathrm{CO}_{2}$ would be between $0.9 \%$ and $0.6 \%$, depending on whether a $\triangle$ SST of 5 or $2{ }^{\circ} \mathrm{C}$ is assumed. The observed increase of $0.7 \%$ would seem to imply, then, that it is not necessary to invoke a large decrease in surface ocean productivity (which would lower atmospheric $\delta^{13} \mathrm{CO}_{2}$ to values more negative than are observed) to explain the $\delta^{13} \mathrm{CO}_{2}$ increase during the transition. What does become necessary, then, is to explain the $0.5 \%$ drop seen between 18 and $16.5 \mathrm{kyr}$ BP.

In the broadest sense, the atmospheric $\delta^{13} \mathrm{CO}_{2}$ record presented here points to the ocean as the predominant source of atmospheric $\mathrm{CO}_{2}$ during the transition. This interpretation follows from two observations. First, even if a change in average global SST alone had caused the increase in $\delta^{13} \mathrm{CO}_{2}$, a realistic $\Delta$ SST would have resulted in an increase of atmospheric $\mathrm{CO}_{2}$ concentration of less than half of what is observed, so there must have been other sources of $\mathrm{CO}_{2}$ during that time. Second, because $\delta^{13} \mathrm{CO}_{2}$ was increasing at a rate equal to or greater than that which rising SST alone would have caused, the additional net $\mathrm{CO}_{2}$ flux must have had a $\delta^{13} \mathrm{CO}_{2}$ equal to, or greater than, that of the coexisting atmosphere, eliminating the terrestrial biosphere as a possible source. The most likely explanation for this is an enhanced flux from the ocean (with a $\delta^{13} \mathrm{C}$ close to that of the atmosphere) which transferred $\mathrm{CO}_{2}$ into the atmosphere at a rate greater than the concurrent uptake of isotopically light $\mathrm{CO}_{2}$ by an expanding terrestrial biosphere. Unfortunately, the constraints imposed by these data are insufficient to allow the identification of a specific cause for the increased flux of $\mathrm{CO}_{2}$ from the ocean to the atmosphere. A better understanding of the carbon cycle depends not only on better models, but on additional experimental constraints on the carbon system, particularly more precise data about changes in SST, the size and composition of the terrestrial biosphere, the growth of coral reefs during periods of sea level rise, marine productivity and the chemical composition of the oceans.

\section{Methods}

All samples were taken from Taylor Dome, Antarctica $\left(770^{\circ} 48^{\prime} \mathrm{S}, 158^{\circ} 43^{\prime} \mathrm{E}\right.$, elevation 2,374 m), drilled in 1993/94. The methods used for determining the $\mathrm{CO}_{2}$ concentration of air trapped in ice and the measurement of its carbonisotope composition are described in detail elsewhere ${ }^{22,23} \cdot \mathrm{CO}_{2}$ concentration measurements have an internal precision of \pm 3 p.p.m.v. $(2 \sigma)$ and are calculated by comparison to three standards of precisely known compositions which are run with every sample. The Craig-corrected ${ }^{24}$ carbon-isotope measurements, performed on our VG Prism II isotope ratio mass spectrometer, have a $1 \sigma$ precision of $\pm 0.075 \%$, based on numerous analyses of the $\mathrm{CO}_{2}$ separated from an atmospheric air standard exposed to uncrushed ice, in order to simulate the conditions of a sample run and to check for fractionation during extraction. $\delta^{13} \mathrm{CO}_{2}$ is reported in normal $\delta$ notation as the per mil difference between the isotopic composition of the sample and standard VPDB carbon, $\left[\left({ }^{13} \mathrm{C} /{ }^{12} \mathrm{C}\right)_{\text {sample }} /\right.$ $\left.\left.\left({ }^{13} \mathrm{C} /{ }^{12} \mathrm{C}\right)_{\text {VPDB }}-1\right] \times 1,000\right)$.

The $\delta^{13} \mathrm{CO}_{2}$ values reported here have been corrected for the gravitational separation of gases of different masses in the firn, and for the presence of $\mathrm{N}_{2} \mathrm{O}$ (which results in isobaric interferences with $\mathrm{CO}_{2}$ during mass spectrometry).
Gravitational separation in the firn ${ }^{25,26}$ was determined by using the values of $\delta^{15} \mathrm{~N}_{2}$ of air trapped in Taylor Dome ice from Sucher ${ }^{27}$, following the approach of Sowers and Bender ${ }^{28}$. The gravitational correction for $\delta^{13} \mathrm{CO}_{2}$ is $\sim 0.005 \%$ o per $\mathrm{m}$. C-isotope data are corrected for the presence of $\mathrm{N}_{2} \mathrm{O}$ on the basis of calibrations performed in our laboratory on $\mathrm{CO}_{2}-\mathrm{N}_{2} \mathrm{O}$ mixtures. The $\mathrm{N}_{2} \mathrm{O}$ concentrations of atmospheric air used for this correction, adapted from Leuenberger and Siegenthaler ${ }^{29}$, are linear interpolations of the following concentrations and dates: 275 p.p.b. (0-9.25 yr BP), 200 p.p.b. (16.1$27.2 \mathrm{kyr}$ вP). The $\mathrm{N}_{2} \mathrm{O}$ correction is $\sim 0.001 \%$ o per p.p.b. of $\mathrm{N}_{2} \mathrm{O}$. The total $1 \sigma$ uncertainty in the reported $\delta^{13} \mathrm{CO}_{2}$ of a single sample, including uncertainties in the gravitational and $\mathrm{N}_{2} \mathrm{O}$ corrections, is $0.085 \%$. Duplicate analyses of samples with air ages of 2.19 and $17.2 \mathrm{kyr}$ BP have a $1 \sigma$ uncertainty of $0.060 \%$ and a triplicate analysis of the sample with an air age of $27.4 \mathrm{kyr}$ вр has a $1 \sigma$ uncertainty of $0.049 \%$. The depth-age scale and air age-ice age differences were calculated using a combination of flow modelling, correlating variations in the $\delta^{18} \mathrm{O}$ of the ice with the well-dated GISP2, and matching atmospheric $\mathrm{CH}_{4}$ concentrations and $\delta^{18} \mathrm{O}$ of $\mathrm{O}_{2}$ with variations seen in GISP2 ${ }^{30}$.

Received 8 October 1998; accepted 7 June 1999.

1. Barnola, J. M., Raynaud, D., Korotkevich, Y. S. \& Lorius, C. Vostok ice core provides 160,000-year record of atmospheric $\mathrm{CO}_{2}$. Nature 329, 408-414 (1987).

2. Neftel, A., Oeschger, H., Staffelbach, T. \& Stauffer, B. $\mathrm{CO}_{2}$ record in the Byrd ice core $50,000-5,000$ years BP. Nature 331, 609-611 (1988).

3. Fischer, H., Wahlen, M., Smith, H. J., Mastroianni, D. \& Deck, B. Ice core records of atmospheric $\mathrm{CO}_{2}$ around the last three glacial terminations. Science 283, 1712-1714 (1999).

4. Petit, J. R. et al. Climate and atmospheric history of the past 420,000 years from the Vostok ice core, Antarctica. Nature 399, 429-436 (1999).

5. Marino, B., McElroy, M. B., Salawitch, R. J. \& Spaulding, W. G. Glacial-to-interglacial variations in the carbon isotopic composition of atmospheric $\mathrm{CO}_{2}$. Nature 357, 461-466 (1992).

6. Anklin, M., Barnola, J.-M., Schwander, J., Stauffer, B. \& Raynaud, D. Processes affecting the $\mathrm{CO}_{2}$ concentrations measured in Greenland ice. Tellus B 47, 461-470 (1995).

7. Delmas, R. J. A natural artefact in Greenland ice core $\mathrm{CO}_{2}$ measurements. Tellus B 45, 391-396 (1993).

8. Barnola, J. M. et al. $\mathrm{CO}_{2}$ evolution during the last millennium as recorded by Antarctic and Greenland ice. Tellus B 47, 264-272 (1995).

9. Indermühle, A. et al. Holocene carbon-cycle dynamics based on $\mathrm{CO}_{2}$ trapped in ice at Taylor Dome, Antarctica. Nature 398, 121-126 (1999).

10. Fairbanks, R. G. The age and origin of the "Younger Dryas Climate Event" in Greenland ice cores. Paleoceanography 5, 937-948 (1990).

11. Leuenberger, M., Siegenthaler, U. \& Langway, C. C. Carbon isotope composition of atmospheric $\mathrm{CO}_{2}$ during the last ice age from an Antarctic ice core. Nature 357, 488-490 (1992).

12. Tans, P. P., Berry, J. A. \& Keeling, R. F. Oceanic ${ }^{13} \mathrm{C} /{ }^{12} \mathrm{C}$ observations: a new window on ocean $\mathrm{CO}_{2}$ uptake. Glob. Biogeochem. Cycles 7, 353-368 (1993).

13. Friedli, H., Lotscher, H., Oeschger, H., Siegenthaler, U. \& Stauffer, B. Ice core record of the ${ }^{13} \mathrm{C} /{ }^{12} \mathrm{C}$ of atmospheric $\mathrm{CO}_{2}$ in the past two centuries. Nature 324, 237-238 (1986).

14. Broecker, W. S. \& Henderson, G. M. The sequence of events surrounding Termination II and their implications for the cause of glacial-interglacial $\mathrm{CO}_{2}$ changes. Paleoceanography 13, 352-364 (1998).

15. Takahashi, T., Olafsson, J., Goddard, J. G., Chipman, D. W. \& Sutherland, S. C. Seasonal variation of $\mathrm{CO}_{2}$ and nutrients in the high-latitude surface oceans: a comparative study. Glob. Biogeochem. Cycles 7, 843-878 (1993).

16. Mook, W. G., Bommerson, J. C. \& Staverman, W. H. Carbon isotope fractionation between dissolved bicarbonate and gaseous carbon dioxide. Earth Planet. Sci. Lett. 22, 169-176 (1974).

17. Weiss, R. F. Carbon dioxide in water and seawater: the solubility of a non-ideal gas. Mar. Chem. 2, 203-215 (1974).

18. Guilderson, T. P., Fairbanks, R. G. \& Rubenstone, J. L. Tropical temperature variations since 20,000 years ago: modulating interhemispheric climate change. Science 263, 663-665 (1994).

19. CLIMAP Project Members Seasonal Reconstructions of the Earth's Surface at the Last Glacial Maximum (Map and Chart Ser, MC-36, Geol. Soc. Am., Boulder, 1981).

20. Fairbanks, R. G. A 17,000-year glacio-eustatic sea level record-influence of glacial melting rates on the Younger Dryas Event and deep-ocean circulation. Nature 342, 637-642 (1989).

21. Duplessy, J. C. et al. Deepwater source variations during the last climatic cycle and their impact on the global deepwater circulation. Paleoceanography 3, 343-360 (1988).

22. Wahlen, M., Allen, D. \& Deck, B. Initial measurements of $\mathrm{CO}_{2}$ concentrations ( 1530 to $1940 \mathrm{AD}$ ) in air occluded in the GISP 2 ice core from central Greenland. Geophys. Res. Lett. 18, 1457-1460 (1991).

23. Smith, H. J., Wahlen, M., Mastroianni, D. \& Taylor, K. C. The $\mathrm{CO}_{2}$ concentration of air trapped in GISP2 ice from the LGM-Holocene transition. Geophys. Res. Lett. 24, 1-4 (1997).

24. Craig, H. Isotopic standards for carbon and oxygen and correction factors for mass-spectrometric analysis of carbon dioxide. Geochim. Cosmochim. Acta 12, 133-149 (1957).

25. Craig, H., Horibe, Y. \& Sowers, T. Gravitational separation of gases and isotopes in polar ice caps. Science 242, 1675-1678 (1988).

26. Schwander, J. The Environmental Record in Glaciers and Ice Sheets (eds Oeschger, H. and Langway, C. C.) 53-67 (Wiley and Sons, New York, 1989).

27. Sucher, C. Trapped Gases in the Taylor Dome Ice Core: Implications for East Antarctic Climate Change. Thesis, Univ. Rhode Island (1997).

28. Sowers, T. \& Bender, M. Elemental and isotopic composition of occluded $\mathrm{O}_{2}$ and $\mathrm{N}_{2}$ in polar ice. J. Geophys. Res. 94, 5137-5150 (1989).

29. Leuenberger, M. \& Siegenthaler, U. Ice-age atmospheric concentration of nitrous oxide from an Antarctic ice core. Nature 360, 449-451 (1988)

30. Steig, E. J. et al. Synchronous climate changes in Antarctica and the North Atlantic. Science 282, 92-95 (1998).

Acknowledgements. We thank G. Hargreaves and J. Fitzpatrick for help obtaining samples, and E. Steig Acknowledgements. We thank G. Hargreaves and J. Fitzpatrick for help obtaining samples, and E. Steig
and E. Brook for sharing their depth-age scales. This work was supported by the NSF and the Director's office at the Scripps Institution of Oceanography.

Correspondence and requests for materials should be addressed to H.J.S. (e-mail: hjsmith@aaas.org). 